\title{
Validated Capillary Zone Electrophoretic Method for Simultaneous Analysis of Benazepril in Combination with Amlodipine Besylate and Hydrochlorothiazide
}

\author{
Hytham M. Ahmed ${ }^{1}$, Tarek S. Belal ${ }^{2}$, Rasha A. Shaalan ${ }^{2,3}$, Fawzy A. El Yazbi ${ }^{2}$ and Sohila M. Elonsy ${ }^{4^{*}}$ \\ 'Pharmaceutical Analysis Department, Faculty of Pharmacy, Menoufia University, Shebin El-Kom, Egypt \\ 'Pharmaceutical Analytical Chemistry Department, Faculty of Pharmacy, University of Alexandria, Alexandria 21521, Egypt \\ ${ }^{3}$ Pharmaceutical Chemistry Department, Faculty of Pharmacy and Drug Manufacturing, Pharos University in Alexandria, Egypt \\ ${ }^{4}$ Pharmaceutical Analytical Chemistry Department, Faculty of Pharmacy, Damanhour University, Damanhour, Egypt
}

Received: 28 Jul 2019; accepted: 14 Sep 2019

\begin{abstract}
In this work, a novel, simple, and quick capillary zone electrophoresis (CZE) method was proposed for simultaneous analysis of benazepril (BEN) with other co-administrated antihypertensive drugs, amlodipine besylate (AML) and hydrochlorothiazide (HCT), using a diode array detector (DAD). A fused silica capillary $(78.5 \mathrm{~cm}$ total length, $70 \mathrm{~cm}$ effective length, and $75 \mu \mathrm{m}$ id) was used in separation using a $40 \mathrm{mM}$ phosphate buffer $\mathrm{pH} 7.5$ as a running background electrolyte (BGE) under a positive potential of $30 \mathrm{KV}$, at a stable temperature of $25^{\circ} \mathrm{C}$ for capillary during separation. Hydrodynamic injections were performed for $12 \mathrm{~s}$ at $50 \mathrm{mbar}$, and detection was performed at $210 \mathrm{~nm}$ for AML and BEN, at $225 \mathrm{~nm}$ for HCT, and at $232 \mathrm{~nm}$ for xipamide (XIP) added as an internal standard (IS). Separation of the three analyzed drugs and the IS was performed in less than 8 min. Migration times were 4.06, 5.23, 6.69, and $7.3 \mathrm{~min}$ for AML, HCT, BEN, and XIP, respectively. The findings proved that the proposed method was linear in the range of $10-80 \mu \mathrm{g} / \mathrm{mL}$ for all drugs with correlation coefficients $>0.9994$. The limit of detection (LOD) values of AML, HCT, and BEN were 1.004, 1.224, and $0.896 \mu \mathrm{g} / \mathrm{mL}$, respectively, whereas the limit of quantification (LOQ) values were 3.124, 3.727, and $2.749 \mu \mathrm{g} / \mathrm{mL}$ for the cited drugs, respectively. Peak identity and purity were confirmed by DAD. The developed CZE method was applied for the analysis of the three antihypertensive drugs successfully in their combined pharmaceutical tablets, and it can be used for the quality control of single-pill combination (SPC) samples of these drugs in short time.
\end{abstract}

Keywords: capillary zone electrophoresis, benazepril, amlodipine besylate, hydrochlorothiazide, pharmaceutical formulations

\section{Introduction}

Hypertension is usually a multifactorial disease, so it is not easy to control and normalize high pressure by blocking only one pressor mechanism. On the other hand, the most important aim for all antihypertensive treatments is to reach normal blood pressure without the addition of intolerable adverse effects. That aim can be achieved by combining drugs with different mechanisms of action. As a result, many single-pill combinations (SPCs) are used today as a promising choice in management of hypertension. This treatment trend makes it more necessary to find suitable analytical methods for simultaneous determination of the co-administered drugs [1]. The present work provides a convenient analytical method for simultaneous analysis of benazepril hydrochloride (BEN) in 2 different binary combinations with amlodipine besylate (AML), and hydrochlorothiazide (HCT) in quality control laboratories (Figure 1).

AML is a dihydropyridine calcium channel blocker [2]. BEN is a non-sulfhydryl angiotensin converting enzyme (ACE) inhibitor. The concomitant administration of AML and BEN proved to have a greater effect in controlling and normalizing systolic and diastolic blood pressures than any of the 2 monotherapies that depended on either AML or BEN alone [2].

* Author for correspondence. E-mail: sohilaonsy@gmail.com; Tel: +20-33092777; Fax: +20-045-3221046-3221047; ORCID: 0000-0002-4964-6238.
BEN and AML combination was reported to be analyzed by several techniques. These reports proposed several spectrophotometric methods [3-7], high-performance liquid chromatography (HPLC) methods [7-15], and only 2 highperformance thin-layer chromatography (HPTLC) methods [16, 17]. 6-Chloro-3,4-dihydro-2H-1,2,4-benzothiadiazine-7sulfonamide 1,1-dioxide HCT is a diuretic of moderate potency [2]. BEN and HCT combination was analyzed through various techniques, such as spectrophotometry [18], spectral chemometric method [19], and some chromatographic methods [20-23]. Regarding capillary electrophoresis (CE), the published reports were concerned with the determination and separation of BEN from other closely related ACE inhibitors [24-26].

A statistical experimental design was used to optimize a $\mathrm{CE}$ separation method for 8 ACE inhibitors including BEN [27]. HCT was determined in its combination with AML and valsar$\tan$ in their combined tablets using CE with UV detection at $230 \mathrm{~nm}$ [28], as well as in its combination with AML and aliskiren using CE with UV detection at $245 \mathrm{~nm} \mathrm{[29].} \mathrm{CE} \mathrm{is} \mathrm{a}$ powerful separation technique; it has several advantages over conventional liquid chromatography (LC) as CE separations are generally able to separate several analytes with high efficiency, in short, analysis time using few nanoliter injection volumes.

CE is conducted mainly in aqueous conditions, so it can easily apply green chemistry roles in contrary to LC

This is an open-access article distributed under the terms of the Creative Commons Attribution-NonCommercial 4.0 International License (https://creativecommons.org/licenses/by-nc/4.0/), which permits unrestricted use, distribution, and reproduction in any medium for non-commercial purposes, provided the original author and source are credited, a link to the CC License is provided, and changes - if any - are indicated. 
<smiles>CCOC(=O)C1=C(COCCN)NC(C)=C(C(=O)OC)C1c1ccccc1Cl</smiles>

AML

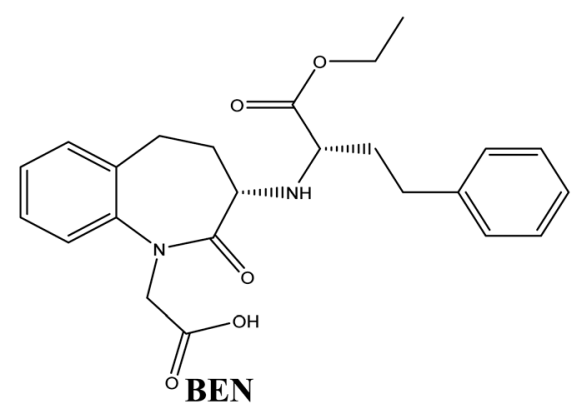<smiles>NS(=O)(=O)c1cc2c(cc1Cl)NCNS2(=O)=O</smiles>

HCT<smiles>Cc1cccc(C)c1NC(=O)c1cc(S(N)(=O)=O)c(Cl)cc1O</smiles>

XIP

Figure 1. Chemical structures of amlodipine besylate (AML), hydrochlorothiazide (HCT), Benazepril (BEN), and Xipamide (XIP)

techniques that consume large volumes of organic solvents. However, reviewing the literature reveals that there is no published method for analysis of BEN in its binary mixtures. Therefore, it was so important to propose a CE method for analysis of BEN in its SPC preparations. This work permits simultaneous analysis of BEN and its co-formulated antihypertensive drugs, AML and HCT, using a simple, selective, and robust $\mathrm{CE}$-diode array detector (CE-DAD) method.

\section{Experimental}

2.1 CE System. The CE system used consisted of an Agilent CE instrument 7100 series (Agilent Technologies Deutschland, GmbH, Hewlett-Packard-Str.8 Waldbronn, Germany) with DAD and a system for data handling containing a computer loaded with Agilent ChemStation software.

Diode Array Detector DAD has the ability of developing electropherograms at more than one wavelength for the same run. Therefore, each compound could be easily measured at its maximum absorption wavelength, thus improving sensitivity of the proposed method. Detection was performed using $\mathrm{DAD}$ at $210 \mathrm{~nm}$ for AML and BEN, at $225 \mathrm{~nm}$ for HCT, and at $232 \mathrm{~nm}$ for XIP. The capillary used in the analyses was a deactivated fused silica capillary (Agilent Technologies, Waldbronn, Germany) of $78.5 \mathrm{~cm}$ total length, $70 \mathrm{~cm}$ effective length, and $75 \mu \mathrm{m}$ internal diameter. Hydrodynamic injection was used with a pressure of 50 mbar for $12 \mathrm{~s}$, where the applied voltage was $30 \mathrm{kV}$.

2.2 Materials and Reagents. Amlodipine besylate was provided by Pfizer Egypt S.A.E., Cairo, Egypt. Hydrochlorothiazide and xipamide were donated by Pharco Pharmaceuticals Co., Alexandria, Egypt. Benazepril was supplied by Novartis Pharma S.A.E., Cairo, Egypt. HPLCgrade methanol was obtained from Sigma-Aldrich (SigmaAldrich Chemie GmbH, Buchs, Switzerland). Reagents of analytical grade such as ortho-phosphoric acid, sodium hydroxide, sodium dihydrogen phosphate, and disodium monohydrogen phosphate were obtained from Oxford Laboratory Reagents Company (Neminath Industrial Estate No. 6, Navghar, Vasai (E), Dist. Thane, Maharashtra, India).
Pharmaceutical preparations containing the analyzed drugs are Loadless ${ }^{\circledR}$ stated to contain $10 \mathrm{mg}$ AML and $20 \mathrm{mg}$ BEN (Gelatin/R. Gp The Arab Company for Gelatin \& Pharmaceutical Products, Alexandria, Egypt). Tablet dosage form containing BEN and HCT combination was made in our laboratory, as it was not available in the local market. The laboratory-prepared tablets are labeled to contain $20 \mathrm{mg}$ BEN and $25 \mathrm{mg}$ HCT per tablet.

\subsection{General Procedure}

2.3.1 Preparation of Running Buffer (BGE). The optimum background electrolyte was a $40 \mathrm{mM}$ phosphate buffer. Anhydrous sodium dihydrogen phosphate $(0.14 \mathrm{~g})$ and anhydrous disodium monohydrogen phosphate $(0.4024)$ were weighed and dissolved in $100 \mathrm{~mL}$ of distilled water. This recipe gave buffer solution with $\mathrm{pH}$ around 7.5 by only $0.3 \mathrm{pH}$ unit, and then the $\mathrm{pH}$ was adjusted to reach 7.5 with $0.01 \%$ ortho-phosphoric acid or $0.5 \mathrm{M}$ sodium hydroxide.

2.3.2 Capillary Conditioning. In the start of each working day and before the first run, the capillary was washed with $0.5 \mathrm{M} \mathrm{NaOH}$ for $20 \mathrm{~min}$, and then with water for $20 \mathrm{~min}$. During the working day, the capillary was flushed using $0.1 \mathrm{M} \mathrm{NaOH}$ for $2.5 \mathrm{~min}$, left for $2.5 \mathrm{~min}$ to ensure complete activation of the internal wall of the fused silica capillary, then rinsed with water for $2.5 \mathrm{~min}$, and finally equilibrated with the running buffer for $10 \mathrm{~min}$. The capillary was flushed with the running buffer for 2 min between each 2 successive injections. Buffer solution was refilled after each 5 successive runs to maintain an acceptable repeatability of run-to-run injections.

2.3.3 Preparation of Standard Solutions and Construction of Calibration Graphs. Standard stock solutions containing $1000 \mu \mathrm{g} / \mathrm{mL}$ of BEN, AML, HCT, and XIP were prepared using HPLC-grade methanol and kept at $+4{ }^{\circ} \mathrm{C}$. Aliquots of standard stock solutions were accurately transferred into a series of $10 \mathrm{~mL}$ volumetric flasks and then diluted with Millipore filtered water to reach the concentration range 10-80 $\mu \mathrm{g} /$ $\mathrm{mL}$ for all the analyzed drugs with an internal standard concentration equals $30 \mu \mathrm{g} / \mathrm{mL}$.

Each concentration was performed in triplicate. Calibration graph were constructed for each drug by plotting peak area ratios against the corresponding concentrations. 


\subsubsection{Preparation of Sample Solutions}

2.3.4.1 Assay of Loadless ${ }^{\circledR}$ capsules. Ten Loadless ${ }^{\circledR}$ capsules were carefully emptied, weighed, and mixed. The average weight per capsule was calculated. A volume of $30 \mathrm{~mL}$ of HPLC-grade methanol was added to an accurate weight of the finely powdered sample equivalent to 1 capsule (5 mg AML base [equivalent to $6.93 \mathrm{mg}$ AML besylate], and $20 \mathrm{mg}$ BEN). The solution was vortexed for $5 \mathrm{~min}$, centrifuged at $5000 \mathrm{rpm}$ for $5 \mathrm{~min}$ to separate clear extract from insoluble powder of excipients, and filtered into a $50-\mathrm{mL}$ volumetric flask. The remained residue was rinsed twice with $5 \mathrm{~mL}$ methanol, which was then collected, added to the filtrate, and completed to final volume with methanol.

Aliquots of the extracted sample solution were spiked with $300 \mu \mathrm{L}$ of XIP internal standard (IS) stock solution and diluted to $10 \mathrm{~mL}$ with water to reach final concentrations within the linearity ranges. The analysis was completed as under "General Procedure". The recovered concentrations were obtained from the constructed calibration graphs.

2.3.4.2 Assay of laboratory-prepared tablets. Benazepril hydrochloride and hydrochlorothiazide are coformulated in the brand Lotensin $\mathrm{HCT}^{\circledR}$ (containing $5 \mathrm{mg} / 6.25 \mathrm{mg}, 10 \mathrm{mg} /$ $12.5 \mathrm{mg}, 20 \mathrm{mg} / 12.5 \mathrm{mg}$, or $20 \mathrm{mg} / 25 \mathrm{mg}$ per tablet). The inactive ingredients of the tablets are cellulose compounds, crospovidone, hydrogenated castor oil, iron oxides, lactose, polyethylene glycol, talc, and titanium dioxide. Benazepril hydrochloride and hydrochlorothiazide coformulated brand is not available in the Egyptian market; therefore, laboratory-prepared tablets were used [30]. The previously mentioned inactive ingredients are not interfering with the proposed method as iron oxides, talc, crospovidone, and titanium dioxide are insoluble in the extraction solvent methanol [31-34]. On the other hand the soluble excipients as hydrogenated castor oil, and polyethylene glycol are not UV absorbing materials.

Five laboratory-prepared tablets containing $20 \mathrm{mg} B E N$ and $25 \mathrm{mg}$ HCT per tablet, in addition to the available tablet excipients, such as magnesium stearate, lactose, starch, and aerosil, were weighed, and finely grinded. An accurate weight of the mixed powder equivalent to $20 \mathrm{mg} B E N$ and $25 \mathrm{mg}$ HCT was accurately transferred to a $50-\mathrm{mL}$ volumetric flask and then treated with the same procedure as that under the assay of Loadless ${ }^{\circledR}$ capsule.

For standard addition assay, aliquots of the standard solutions were added to the corresponding sample solutions to obtain total concentrations within the previously specified ranges then treated as under General Procedure. Recovered concentrations were obtained by comparing the analyte response with the increment response detected after addition of the standard.

Moreover, placebo samples were prepared including the following excipients (maize starch and avicel pH101) as a placebo for capsules. Another placebo containing magnesium stearate, lactose, starch, and aerosil was prepared as a placebo for tablets. A suitable weight of each placebo equal to the average weight of 1 capsule or 1 tablet after subtraction of the weights of the active components was treated similarly to that under assay of capsules and tablets.

2.4 Ethical Approval. This article does not contain any studies with human participants or animals performed by any of the authors.

\section{Results and Discussion}

3.1 Method Optimization. Separation of analytes using capillary zone electrophoresis is affected by many parameters. In the proposed CZE method the following parameters were studied; buffer $\mathrm{pH}$, buffer concentration, solvent selection, sample injection, and selection of detection wavelength.
3.1.1 Buffer $\mathbf{p H}$. The $\mathrm{pH}$ of BGE has a crucial role in analytes' separations in $\mathrm{CE}$, especially for analytes that have weak acidic or weak basic properties. AML has $\mathrm{p} K_{\mathrm{a}}$ values of 8.7 [35] and 9.45 [36] and is stated to be predominantly present in the positively ionized form at a physiologic pH (7.4) [37]. HCT has acidic properties due to its sulfonamide groups, with $\mathrm{p} K_{\mathrm{a}}$ values of 7.9 and 9.09 [38], so it may be unionized at the working BGE. Finally, BEN has $\mathrm{pKa}$ values of 3.1 and 5.3 [39], and as most ACE inhibitors, its carboxylic group is completely ionized at physiologic $\mathrm{pH}$ [40]. The final chosen $\mathrm{pH}$ of the background electrolytes is 7.5 , so the three drugs are present in the following forms: AML is positively charged due to ionization of the basic amino group, HCT is predominantly uncharged, and BEN is negatively charged due to its ionized carboxylic group. Accordingly, the migration of the analyzed drugs in the present work can be explained, as AML gets out of the capillary first as it carries a positive charge, followed by the uncharged HCT, and finally the negatively charged BEN.

3.1.2 Buffer Concentration. Buffer concentration has a significant effect on the separation performance as it affects the amount of the produced current in the capillary, electroosmotic flow (EOF), and also affects peak symmetry. Examination of this parameter was done by varying the phosphate buffer concentrations from 10 to $50 \mathrm{mM}$. A small change occurs in migration times, but a significant improvement of peak symmetry and shape occurs by increasing buffer concentration especially for HCT and BEN, as shown in Figure 2.

Resolution was also improved mainly between BEN and the internal standard XIP as the resolution value between them was 3.03 in $10 \mathrm{mM}$ buffer, but for $40 \mathrm{mM}$ buffer, the resolution value was increased to 6.02. Thus, a phosphate buffer concentration of $40 \mathrm{mM}$ was chosen to improve both symmetry and resolution.

3.1.3 Solvent Selection. For selection of suitable diluting solvent, background electrolyte (BGE) and water were both
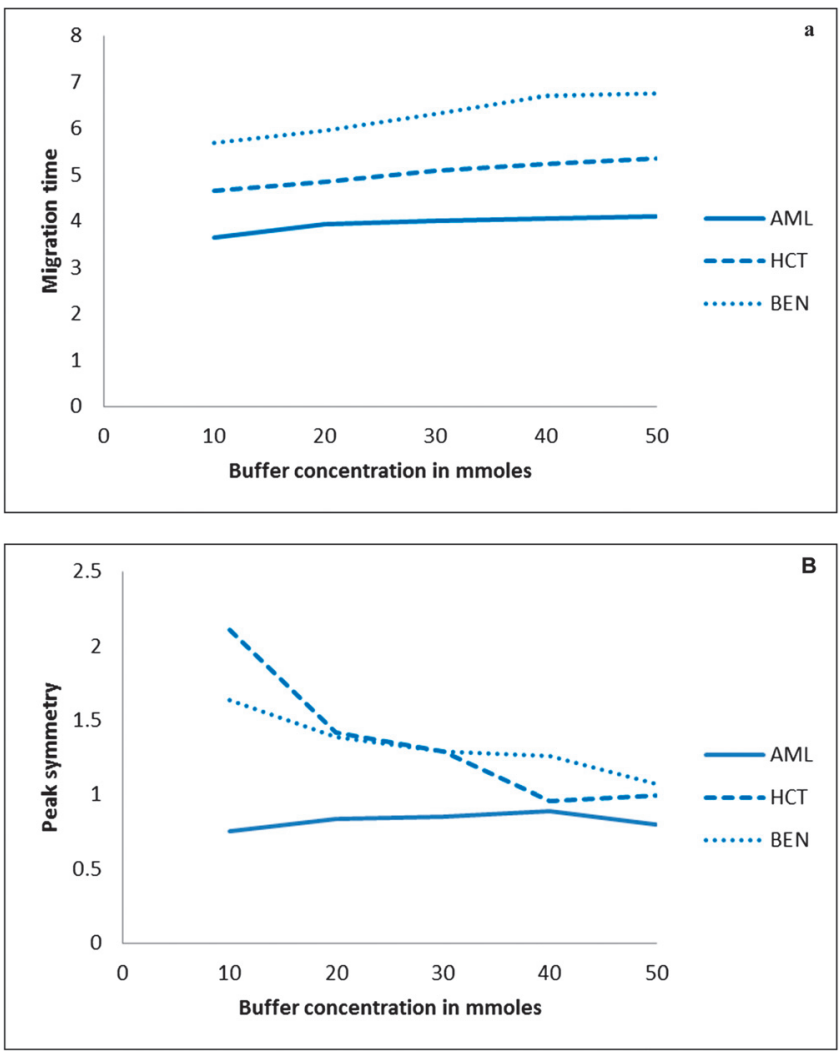

Figure 2. Effect of buffer concentration on (a) migration times of the tested drugs and (b) peak symmetry 
tried. There was no significant difference in peak areas of injections using BGE or water. However, using water as a diluting solvent gave better peak shape, which is attributed to sample high-field stacking occurring due to lower ionic strength diluent in the sample (water) compared to the higher ionic strength of BGE that causes ions to migrate faster and stack as a sharp peak [41].

3.1.4 Sample Injection and Use of Internal Standard. A range of 3.0-14.0 s injection times was examined at a pressure of 50 mbar. Longer injection time improved the signal response (peak area), but further increase in injection time led to peak deformation and loss of linear response. The $12 \mathrm{~s}$ injection time gave optimum results. Addition of the internal standard in CE methods is used to decrease possible errors due to injection or fluctuations in migration times and to enhance quantitative determination, so xipamide (XIP) is used as the internal standard.

3.1.5 Selection of Detection Wavelength. DAD has the advantage of measuring analytes at more than one wavelength. Thus, each compound could be measured at its wavelength of maximum absorption, which leads to a higher sensitivity.

AML and BEN were measured at $210 \mathrm{~nm}$, while HCT was measured at $225 \mathrm{~nm}$ providing better sensitivity for HCT analysis. A $232 \mathrm{~nm}$ wavelength was selected for the internal standard XIP. The developed method allowed the efficient separation of the analyzed drugs in the presence of the internal standard in an acceptable time less than 8 min. Figure 3 represents typical electropherograms of the CZE separation of the cited drugs at the two selected wavelengths with migration times 4.06, 5.23, 6.69, and 7.25 min for AML, HCT, BEN, and XIP, respectively. The previously optimized method shows well-defined peaks of AML, HCT, BEN, and XIP. For system suitability parameters, retention factors $(k)$, selectivity $(\alpha)$, resolution, and number of theoretical plates $(N)$ values for the analyzed drugs are fully described in Table 1.

3.2 Method Validation. The proposed method was validated for linearity, range, limit of detection (LOD), limit of quantitation (LOQ), accuracy, precision, specificity, and robustness. The suggested method was validated according to the published guidelines of the International Conference on Harmonization ( $\mathrm{ICH})$ guidelines [42].

3.2.1 Linearity and Concentration Ranges. The linear regression equations were generated by least squares treatment of the calibration data. The linearity estimated from calibration curves was confirmed by high values of correlation coefficients (where $r=0.9995$ for AML, $r=0.9997$ for HCT, and $r=0.9998 \mathrm{BEN})$ in a linearity range of $10-80 \mu \mathrm{g} / \mathrm{mL}$ for the 3 drugs. Performance values and statistical data such as linear regression equations, concentration ranges, correlation coefficients, and standard deviations of residuals $\left(S_{y / x}\right)$, of intercept $\left(S_{\mathrm{a}}\right)$, and of slope $\left(S_{\mathrm{b}}\right)$ all are presented in Table 2. Linearity can be evaluated by calculating the value of relative standard
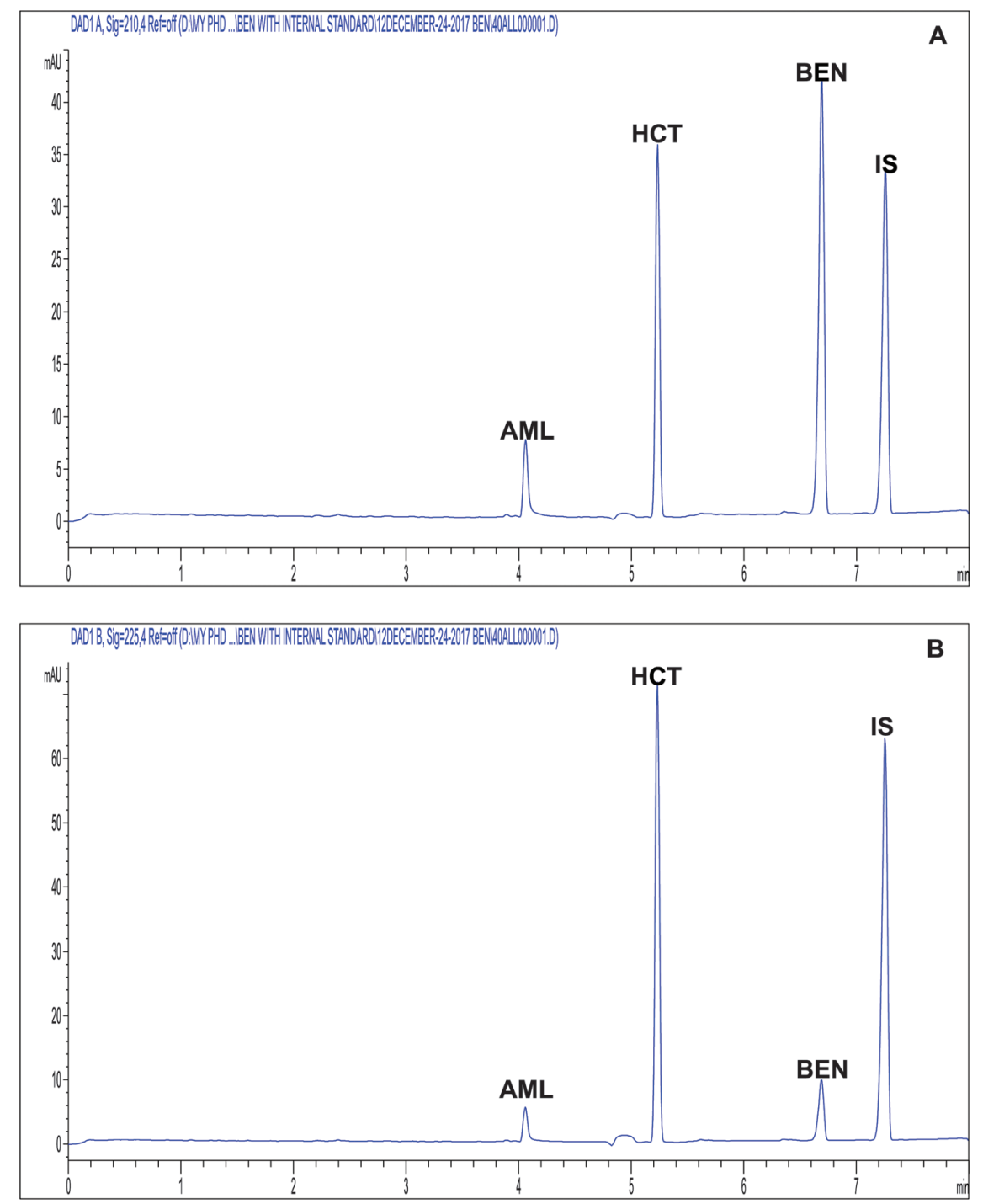

Figure 3. CE electropherograms of a mixture containing $40 \mu \mathrm{g} / \mathrm{mL}$ of AML, HCT, BEN, and $30 \mu \mathrm{g} / \mathrm{mL}$ XIP at (a) $210 \mathrm{~nm}$ for AML and BEN and (b) $225 \mathrm{~nm}$ for HCT 
Table 1. System suitability parameters for CZE-DAD analysis of AML, HCT, and BEN mixtures

\begin{tabular}{lccc}
\hline Parameter & AML & HCT & BEN \\
\hline$t_{\mathrm{R}} \pm$ SD $(\min )$ & $4.06 \pm 0.18$ & $5.23 \pm 0.16$ & $6.69 \pm 0.14$ \\
Retention factors $(k)$ & 1.71 & 2.49 & 3.46 \\
Theoretical plates $(N)$ & 40,474 & 77,642 & $8.25 \pm 0.18$ \\
US Pharmacopeia tailing factor & 1.09 & 0.94 & 3.83 \\
Selectivity $(\alpha)$ & - & 1.46 & 0.86 \\
Resolution $\left(R_{\mathrm{s}}\right)$ & - & 14.92 & 1.39 \\
\hline
\end{tabular}

Table 2. Statistical analytical parameters calculated for analysis of AML, HCT, and BEN mixtures using the proposed CZE-DAD method

\begin{tabular}{|c|c|c|c|}
\hline Parameter & AML & HCT & $\mathrm{BEN}$ \\
\hline Wavelength (nm) & 210 & 225 & 210 \\
\hline Concentration range $(\mu \mathrm{g} / \mathrm{mL})$ & $10-80$ & $10-80$ & $10-80$ \\
\hline Intercept $(a)$ & -0.006 & 0.014 & 0.026 \\
\hline$S_{\mathrm{a}}{ }^{a}$ & 0.002 & 0.006 & 0.006 \\
\hline Slope $(b)$ & 0.003 & 0.013 & 0.015 \\
\hline$S_{\mathrm{b}}{ }^{b}$ & $3.46 \times 10^{-5}$ & $1.26 \times 10^{-4}$ & $1.26 \times 10^{-4}$ \\
\hline RSD $\%$ of the slope $\left(S_{\mathrm{b}} \%\right)$ & 1.153 & 0.969 & 0.840 \\
\hline Correlation coefficient (r) & 0.9995 & 0.9997 & 0.9998 \\
\hline$R$ square & 0.9990 & 0.9994 & 0.9996 \\
\hline$S_{\mathrm{y} / \mathrm{x}}{ }^{c}$ & 0.002 & 0.008 & 0.008 \\
\hline$F^{d}$ & 6451 & 10,775 & 14,421 \\
\hline Significance $\mathrm{F}$ & $2.51 \times 10^{-10}$ & $5.39 \times 10^{-11}$ & $2.25 \times 10^{-11}$ \\
\hline $\operatorname{LOD}^{e}(\mu \mathrm{g} / \mathrm{mL})$ & 1.004 & 1.224 & 0.896 \\
\hline $\mathrm{LOQ}^{f}(\mu \mathrm{g} / \mathrm{mL})$ & 3.124 & 3.727 & 2.749 \\
\hline \multicolumn{4}{|c|}{$\begin{array}{l}{ }^{a} \text { Standard deviation of the intercept. } \\
{ }^{b} \text { Standard deviation of the slope. } \\
{ }^{c} \text { Standard deviation of residuals. } \\
{ }^{d} \text { Variance ratio equals the mean of squares due to regression divided by } \\
\text { the mean of squares about regression (due to residuals). } \\
{ }^{e} \text { Limit of detection. } \\
{ }^{f} \text { Limit of quantification. }\end{array}$} \\
\hline
\end{tabular}

deviation $(\mathrm{RSD} \%)$ of the slope $\left(S_{\mathrm{b}} \%\right)$, which did not exceed $1.2 \%$. Moreover, linearity can be further guaranteed by the analysis of variance (ANOVA) test. The most important statistic in this test is the $F$-value, which is the ratio of the mean of squares due to regression divided by the mean of squares due to residuals. High $F$-values reveal an increase in the mean of squares due to regression and a decrease in the mean of squares due to residuals. The greater is the mean of squares due to regression, the steeper is the regression line. The smaller is the mean of squares due to residuals, the lesser is the scatter of experimental points around the regression line. Consequently, regression lines with high $F$-values (low significance $F$ ) are much better than those with lower ones. Good regression lines show high values for both $r$ and $F$ statistical parameters [43, 44].

3.2.2 Detection and Quantification Limits. According to the ICH guidelines, LOD is defined as the analyte concentration that has a signal-to-noise ratio of $3: 1$. For LOQ, the ratio is considered 10:1. The values of LOD and LOQ for AML, $\mathrm{HCT}$, and BEN were calculated according to the ICH and presented in Table 2, and those values confirm the acceptable sensitivity of the developed CE procedure.

3.2.3 Accuracy and Precision. The intra-day precision and accuracy of the studied method were estimated by using 3 replicate determinations at 3 concentration levels for each compound within 1 day.

On the other hand, the between-day (inter-day) precision were examined by analyzing 3 replicates at the same 3 concentration levels repeated on 3 different days. Statistical evaluation of inter-day and intra-day data of AML, HCT, and BEN showed the low RSD\% of the found concentration values of each compound, which did not exceed $2 \%$ (Table 3 ), using the proposed method.

These low RSD\% values proved the method precision. The $\mathrm{Er} \%$ values of AML, HCT, and BEN were less than $2 \%$, proving the accuracy of method.
3.2.4 Selectivity. Selectivity was studied by analyzing several laboratory-prepared mixtures of the 3 compounds at different concentrations within their acceptable linear ranges according to the proposed method. These mixtures represent various ratios between the tested drugs, representing higher or lower ratios than those present in the combined dosage forms. Table 4 shows satisfactory values of $\mathrm{RSD} \%$ and $\mathrm{Er} \%$, thus proving acceptable selectivity of the proposed method and showing its ability to separate and quantify the analyzed drugs in different ratios. As the DAD allows verification of peak purity, there was no sign of any co-eluted peaks from the inactive components. In addition, the superimpositions of a set of spectra at different positions of each peak confirm peak purity and method selectivity (Figure 4 (A1, B1, C1)). The similarity factor of the peak improves the sensitivity and reliability of the peak purity evaluation by using all the spectra acquired during the elution or migration of a peak rather than just 3 or 4 spectra. Figure 4 (A2, B2, C2) indicated high similarity of each peak as the similarity curve did not exceed the threshold value of the noise indicated by red colored area.

3.2.5 Robustness. The robustness of the proposed method was studied by evaluating the constancy of both peak area ratios and migration times after some tested changes in experimental parameters of the proposed method. The study was performed on a $40 \mu \mathrm{g} / \mathrm{mL}$ mixture of each drug and $30 \mu \mathrm{g} /$ $\mathrm{mL}$ of IS. The studied parameters include phosphate buffer concentration $40 \pm 2 \mathrm{mM}$, buffer $\mathrm{pH} 7.5 \pm 0.2$, and wavelength $210 \pm 2 \mathrm{~nm}$ and $225 \pm 2 \mathrm{~nm}$. Analysis was performed by triplicate injections with only single change occurred at a

Table 3. Precision and accuracy for the analysis of laboratory-prepared mixtures of the standard AML, HCT, and BEN mixtures using the proposed CZE-DAD method

\begin{tabular}{|c|c|c|c|c|}
\hline Analyte & $\begin{array}{c}\text { Nominal } \\
\text { value }(\mu \mathrm{g} / \mathrm{mL})\end{array}$ & $\begin{array}{l}\text { Found } \pm \mathrm{SD}^{a} \\
\quad(\mu \mathrm{g} / \mathrm{mL})\end{array}$ & $\begin{array}{l}\text { RSD } \\
(\%)^{b}\end{array}$ & $\begin{array}{c}E_{\mathrm{r}} \\
(\%)^{c} \\
\end{array}$ \\
\hline \multirow{7}{*}{ AML } & & Within-day & & \\
\hline & 20 & $20.02 \pm 0.33$ & 1.65 & 0.10 \\
\hline & 40 & $39.96 \pm 0.68$ & 1.70 & -0.10 \\
\hline & 80 & $\begin{array}{l}80.22 \pm 0.62 \\
\text { Between-days }\end{array}$ & 0.77 & 0.28 \\
\hline & 20 & $20.38 \pm 0.15$ & 0.74 & 1.90 \\
\hline & 40 & $39.81 \pm 0.26$ & 0.65 & -0.47 \\
\hline & 80 & $\begin{array}{r}80.87 \pm 0.99 \\
\text { Within-day }\end{array}$ & 1.22 & 1.09 \\
\hline \multirow{6}{*}{ HCT } & 20 & $20.03 \pm 0.20$ & 1.00 & 0.15 \\
\hline & 40 & $39.58 \pm 0.28$ & 0.71 & -1.05 \\
\hline & 80 & $\begin{array}{l}80.48 \pm 0.35 \\
\text { Between-days }\end{array}$ & 0.43 & 0.60 \\
\hline & 20 & $20.18 \pm 0.38$ & 1.88 & 0.90 \\
\hline & 40 & $39.51 \pm 0.21$ & 0.53 & -1.23 \\
\hline & 80 & $\begin{array}{l}80.53 \pm 0.35 \\
\text { Within-day }\end{array}$ & 0.43 & 0.66 \\
\hline \multirow{6}{*}{ BEN } & 20 & $19.86 \pm 0.18$ & 0.91 & -0.70 \\
\hline & 40 & $39.62 \pm 0.40$ & 1.01 & -0.95 \\
\hline & 80 & $\begin{array}{l}79.86 \pm 0.52 \\
\text { Between-days }\end{array}$ & 0.65 & -0.18 \\
\hline & 20 & $20.05 \pm 0.17$ & 0.85 & 0.25 \\
\hline & 40 & $39.89 \pm 0.75$ & 1.88 & -0.28 \\
\hline & 80 & $79.82 \pm 0.57$ & 0.71 & -0.23 \\
\hline
\end{tabular}

${ }^{a}$ Mean \pm standard deviation for 3 replicates of each concentration.

$b_{\%} \%$ Relative standard deviation.

$c_{0} \%$ Relative error. 
Table 4. Analysis of AML, HCT, and BEN laboratory-prepared mixtures using the proposed CZE-DAD method

\begin{tabular}{|c|c|c|c|c|c|c|c|c|c|c|c|}
\hline \multicolumn{3}{|c|}{$\overline{\text { Nominal value }(\mu \mathrm{g} / \mathrm{mL})}$} & \multicolumn{3}{|c|}{ Found $\pm \mathrm{SD}^{a}(\mu \mathrm{g} / \mathrm{mL})$} & \multicolumn{3}{|c|}{$\operatorname{RSD}(\%)^{b}$} & \multicolumn{3}{|c|}{$\overline{\mathrm{E}_{\mathrm{r}}(\%)^{c}}$} \\
\hline$\overline{\mathrm{AML}}$ & HCT & BEN & AML & HCT & BEN & $\overline{\mathrm{AML}}$ & HCT & $\mathrm{BEN}$ & $\overline{\mathrm{AML}}$ & HCT & BEN \\
\hline$\overline{10}$ & 12.5 & 20 & $10.14 \pm 0.15$ & $12.31 \pm 0.21$ & $19.84 \pm 0.20$ & 1.48 & 1.71 & 1.01 & 1.40 & -1.52 & -0.80 \\
\hline 20 & 25 & 40 & $20.08 \pm 0.15$ & $25.01 \pm 0.11$ & $39.54 \pm 0.56$ & 0.75 & 0.44 & 1.42 & 0.40 & 0.04 & -1.15 \\
\hline 20 & 20 & 20 & $20.13 \pm 0.37$ & $19.61 \pm 0.31$ & $20.29 \pm 0.29$ & 1.84 & 1.58 & 1.43 & 0.65 & -1.95 & 1.45 \\
\hline 20 & 20 & 80 & $20.28 \pm 0.31$ & $20.25 \pm 0.14$ & $79.11 \pm 0.39$ & 1.53 & 0.69 & 0.49 & 1.40 & 1.25 & -1.11 \\
\hline 20 & 80 & 20 & $20.28 \pm 0.23$ & $80.99 \pm 1.13$ & $19.69 \pm 0.31$ & 1.13 & 1.40 & 1.57 & 1.40 & 1.24 & -1.55 \\
\hline 80 & 20 & 20 & $80.17 \pm 0.93$ & $19.93 \pm 0.23$ & $20.04 \pm 0.24$ & 1.16 & 1.15 & 1.20 & 0.21 & -0.35 & 0.20 \\
\hline 40 & 40 & 40 & $39.87 \pm 0.67$ & $39.39 \pm 0.21$ & $39.64 \pm 0.37$ & 1.68 & 0.53 & 0.93 & -0.33 & -1.53 & -0.90 \\
\hline & $\begin{array}{l}\text { ard } \\
\text { tanda } \\
\text { aror. }\end{array}$ & $\begin{array}{l}n \text { for } \\
\text { tion. }\end{array}$ & erminations. & & & & & & & & \\
\hline
\end{tabular}
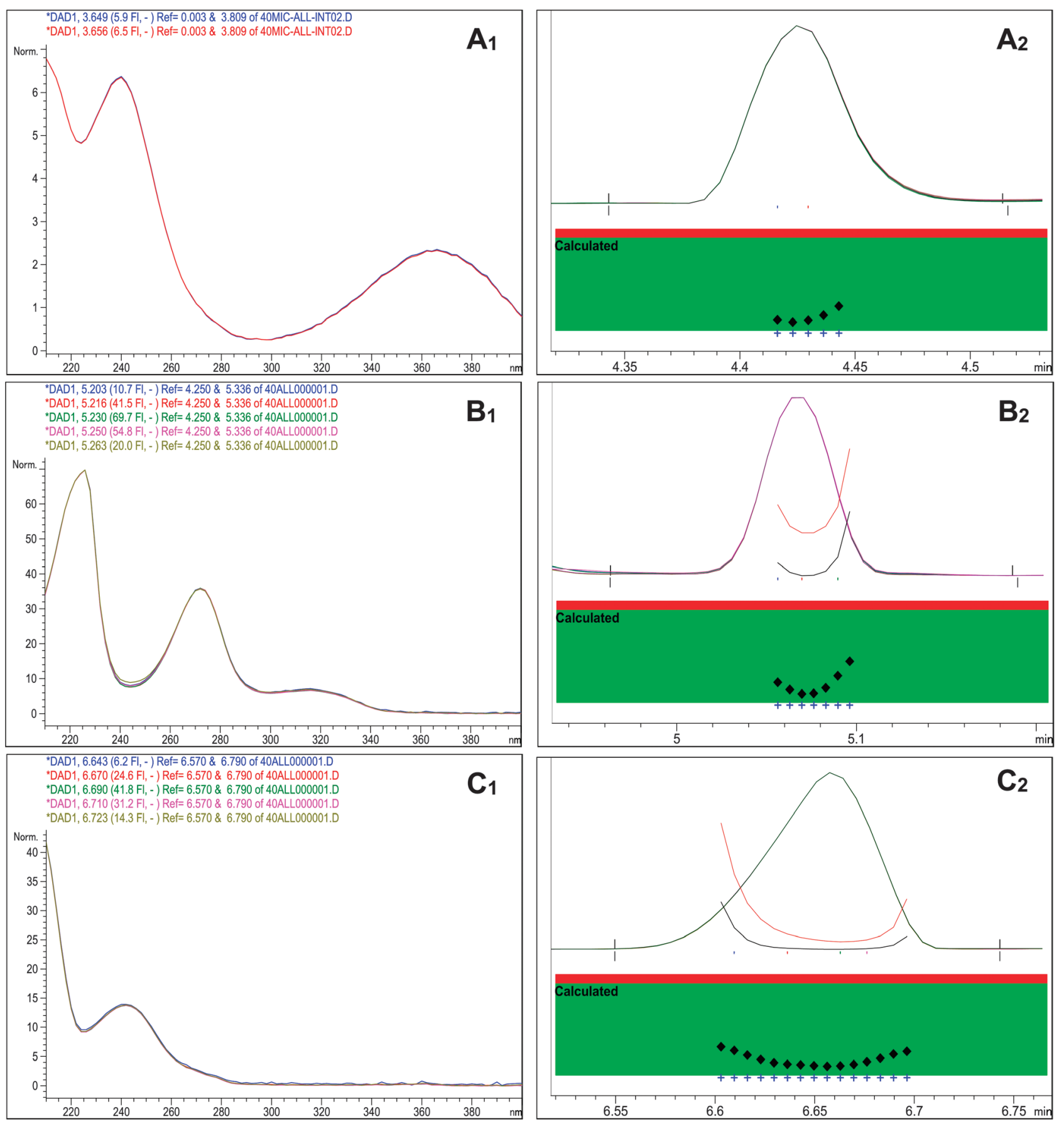

Figure 4. Absorption spectrum of $40 \mu \mathrm{g} / \mathrm{mL}$ mixture of $\left(a_{1}\right)$ AML, $\left(b_{1}\right)$ HCT, and $\left(c_{1}\right)$ BEN measured at 5 different time intervals across the CE peak, while $a_{2}, b_{2}$, and $c_{2}$ represent the purity plot for AML, HCT, and BEN peaks, respectively

time. The method proved to be robust, as the studied changes did not significantly affect peak area ratios or migration times of the tested drugs as proved by the RSD\% values (Table 5).
3.2.6 Stability of Solutions. The stability of working sample solutions were carried out for $20 \mu \mathrm{g} / \mathrm{mL}$ mixture solution of AML, HCT, and BEN with $30 \mu \mathrm{g} / \mathrm{mL}$ XIP IS kept at $4{ }^{\circ} \mathrm{C}$ for 
Table 5. Robustness evaluation for the analysis of AML, HCT, and BEN mixtures using the proposed CZE-DAD method

\begin{tabular}{|c|c|c|c|c|}
\hline \multirow[t]{2}{*}{ Parameter } & \multicolumn{4}{|c|}{ AML } \\
\hline & Peak area ratio $\pm S D$ & RSD $\%$ & Migration time \pm SD & $\overline{\mathrm{RSD} \%}$ \\
\hline Buffer concentration $40 \mathrm{mM} \pm 2$ & $0.11 \pm 0.001$ & 0.91 & $3.96 \pm 0.09$ & 2.27 \\
\hline $\mathrm{pH}$ value $7.5 \pm 0.2$ & $0.11 \pm 0.001$ & 0.91 & $3.97 \pm 0.08$ & 2.02 \\
\hline Wavelength $210 \pm 2 \mathrm{~nm}$ & $0.10 \pm 0.001$ & 1.00 & & \\
\hline Parameter & Peak area ratio $\pm S D$ & RSD \% & Migration time \pm SD & $\mathrm{RSD} \%$ \\
\hline Buffer concentration $40 \mathrm{mM} \pm 2$ & $0.54 \pm 0.010$ & 1.85 & $5.18 \pm 0.11$ & 2.12 \\
\hline $\mathrm{pH}$ value $7.5 \pm 0.2$ & $0.56 \pm 0.010$ & 1.79 & $5.17 \pm 0.08$ & 1.55 \\
\hline Wavelength $225 \pm 2 \mathrm{~nm}$ & $0.54 \pm 0.010$ & 1.85 & & \\
\hline Parameter & Peak area ratio $\pm S D$ & \multicolumn{2}{|c|}{ BEN } & RSD $\%$ \\
\hline Buffer concentration $40 \mathrm{mM} \pm 2$ & $0.62 \pm 0.010$ & 1.61 & $6.26 \pm 0.13$ & 2.08 \\
\hline $\mathrm{pH}$ value $7.5 \pm 0.2$ & $0.64 \pm 0.011$ & 1.72 & $6.30 \pm 0.14$ & 2.22 \\
\hline Wavelength $210 \pm 2 \mathrm{~nm}$ & $0.60 \pm 0.010$ & 1.67 & & \\
\hline
\end{tabular}

1 week. The investigation demonstrated that the three selected drugs were stable under these conditions, and no chromatographic changes were detected. There was no significant change in peak areas and migration times of the analyzed drugs as the \%RSD was not more than 1.9 for both peak areas and migration times. The absorption spectra of the solutions were also checked, and they were found to be unchanged. The stock solutions were found to be stable for at least 2 weeks when kept at $4{ }^{\circ} \mathrm{C}$. The calculated concentrations of the newly prepared solutions and those aged for 2 weeks were analyzed using the proposed method, and RSD\% was found to be less than $2.0 \%$.

3.3 Assay of Dosage Forms. The proposed CZE method was used for the assay of BEN in Loadless ${ }^{\circledR}$ capsules and laboratory-prepared tablets for its mixture with HCT. Selective electropherograms obtained from the capsules extract and laboratory-made tablet extract are shown in Figures 5 and 6, respectively, where the extracted drugs appeared at their specific migration times. No other peaks were detected from any inactive ingredients in the mentioned electropherograms (Figures 5 and 6) or after injecting a solution extracted from the capsule and tablet placebo containing possible placebo ingredients (maize starch, microcrystalline cellulose, magnesium stearate, hydroxypropyl methylcellulose (HPMC), lactose, and colloidal silica (Aerosil)).

DAD proves the peak purity as no signs of co-elution from any of the inactive components were detected. Recoveries were obtained using standard addition method as it is a useful method to detect possible matrix interferences and is used to prove selectivity of the analytical method in analysis of the targeted compounds. The assay data showed satisfactory accuracy and precision as evidenced by the calculated values of \%recovery, SD, and RSD\% (Table 6).

\section{Conclusion}

A simple, fast, and robust CZE method was performed and evaluated for the simultaneous analysis of AML, HCT, and $\mathrm{BEN}$ in 2 pharmaceutical combinations for the first time. To the best of our knowledge, no other published $\mathrm{CE}$ reports were developed yet for the determination of BEN in its SPC. The method shows acceptable performance with respect to all validation parameters, and it offers an inexpensive and precise way for the analysis of the 3 drugs in the combined pharmaceutical preparations. Moreover, the use of DAD offers the great advantage of peak purity verification. Our method proves that CE could be used as an alternative to HPLC, and it is also convenient for routine analysis.

\section{Conflict of Interest}

The authors declare that they have no conflict of interest.

\section{Funding Sources}

This research did not receive any specific grant from funding agencies in the public, commercial, or not-for-profit sectors.

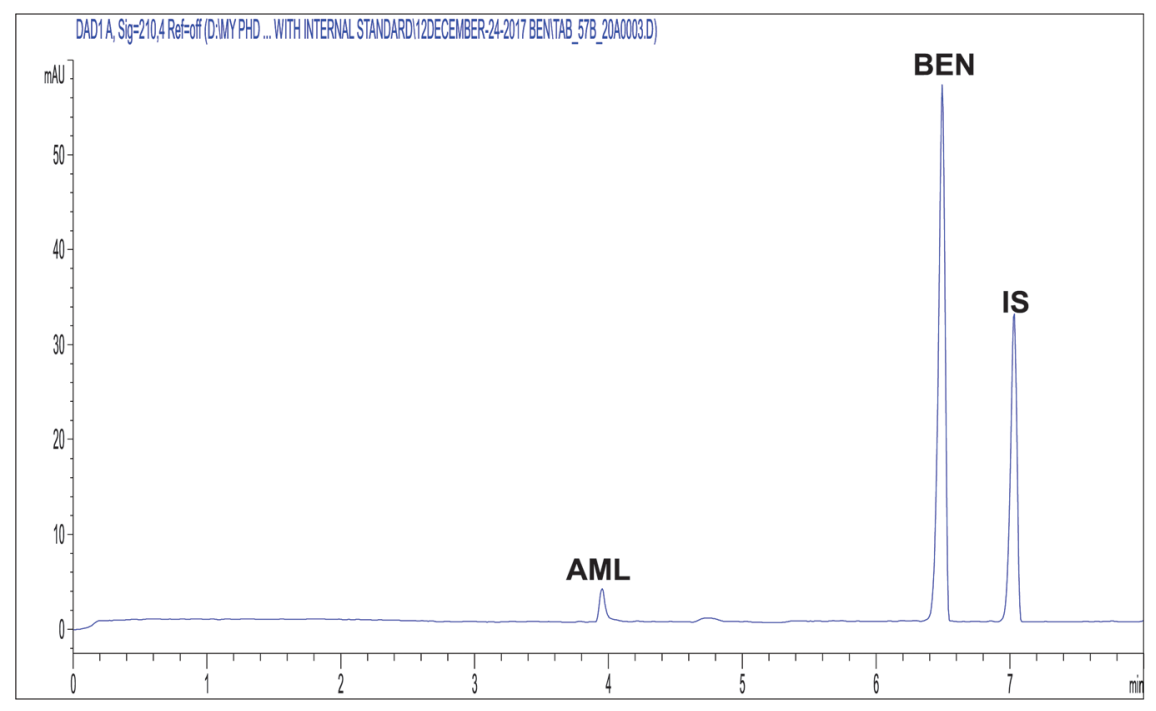

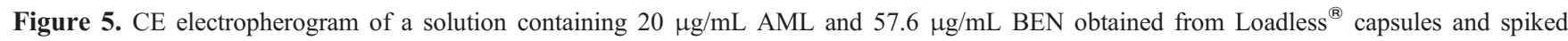
with $30 \mu \mathrm{g} / \mathrm{mL}$ IS at $210 \mathrm{~nm}$ 

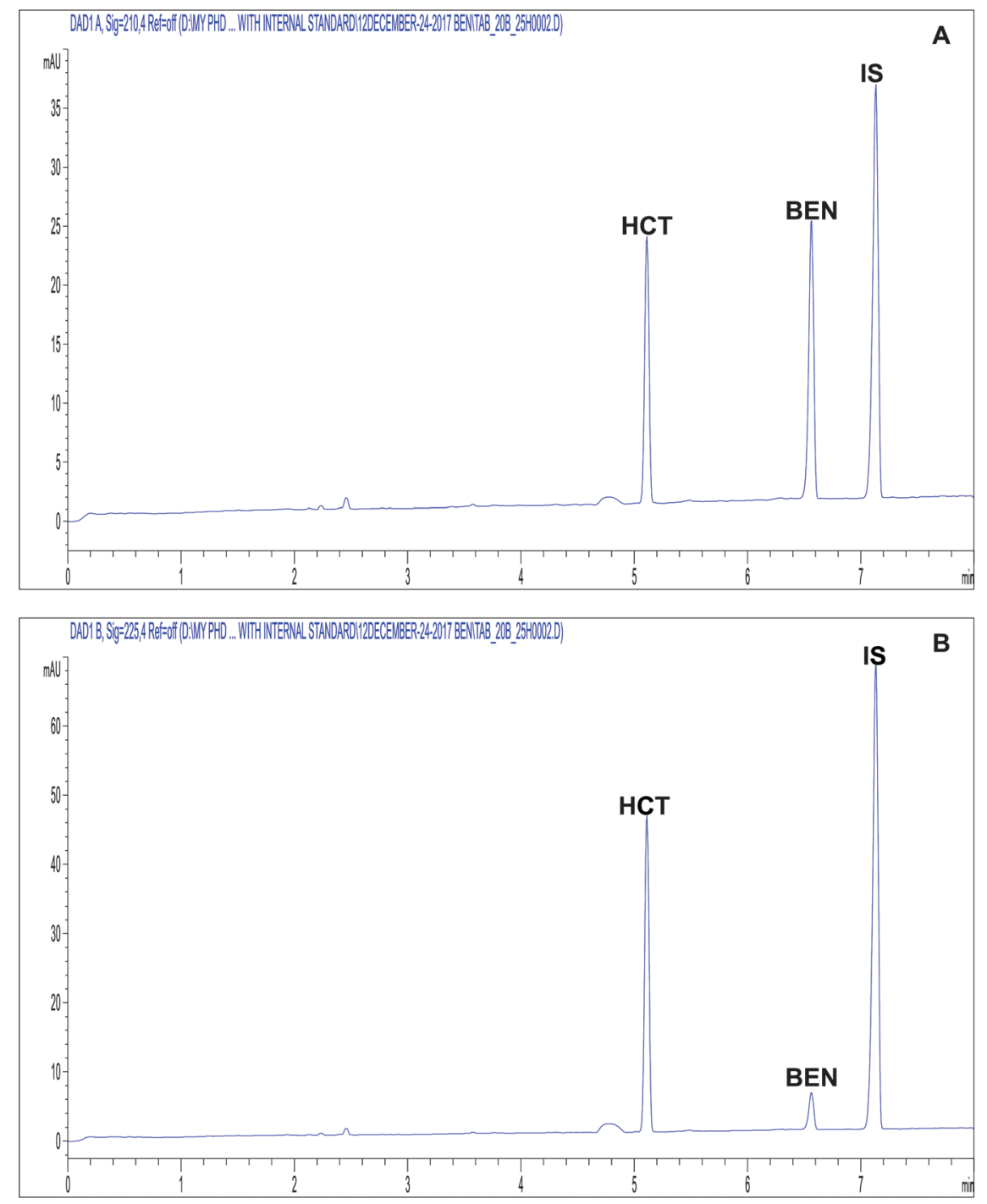

Figure 6. CE electropherograms of a solution containing $20 \mu \mathrm{g} / \mathrm{mL}$ BEN and $25 \mu \mathrm{g} / \mathrm{mL}$ HCT obtained from laboratory-prepared tablets and spiked with $30 \mu \mathrm{g} / \mathrm{mL}$ IS (a) at $210 \mathrm{~nm}$ (b) at $225 \mathrm{~nm}$

Table 6. Application of the proposed CZE-DAD method to the analysis of BEN-AML and BEN-HCT mixtures in SPC (Loadless ${ }^{\circledR}$ capsules and laboratory-prepared tablets of BEN and HCT)

\begin{tabular}{|c|c|c|c|c|}
\hline \multirow[t]{2}{*}{ Loadless $^{\circledR}$ capsules } & \multicolumn{2}{|c|}{ External Standard } & \multicolumn{2}{|c|}{ Standard Addition } \\
\hline & BEN & AML & BEN & AML \\
\hline $\begin{array}{l}\text { \%Recovery } \pm \mathrm{SD}^{a} \\
\operatorname{RSD}^{b}{ }^{a}\end{array}$ & $\begin{array}{c}100.37 \pm 0.38 \\
0.38\end{array}$ & $\begin{array}{c}99.45 \pm 0.99 \\
0.99\end{array}$ & $\begin{array}{c}99.82 \pm 0.96 \\
0.96\end{array}$ & $\begin{array}{c}100.20 \pm 1.48 \\
1.48\end{array}$ \\
\hline Laboratory-prepared tablets & External Standard & HCT & Standard Addition & HCT \\
\hline $\begin{array}{l}\% \text { Recovery } \pm \text { SD }^{a} \\
\operatorname{RSD}^{b}\end{array}$ & $\begin{array}{c}99.78 \pm 0.41 \\
0.41\end{array}$ & $\begin{array}{c}100.18 \pm 0.69 \\
0.69\end{array}$ & $\begin{array}{c}99.50 \pm 0.81 \\
0.81\end{array}$ & $\begin{array}{c}99.57 \pm 1.15 \\
1.16\end{array}$ \\
\hline
\end{tabular}

\section{References}

1. Gradman, A. H.; Basile, J. N.; Carter, B. L.; Bakris, G. L. J. Am. Soc. Hypertens. 2010, 4, 90

2. Sweetman, S. C. Martindale-The Complete Drug Reference, Thirtysixth edition, The Pharmaceutical Press, London, UK, 2009, 1214.

3. Karpińska, J. Talanta 2004, 64, 801.

4. Pawar, P. Y.; Joshi, R. S.; Sandhan, V.; Wagh, S.; , Jangale, K.Der Pharm. Lett. 2011, 3, 397. 371

5. Vathia, A.; Suchak, K.; Misra, M. Int. J. Pharm. Pharm. Sci. 2013, 5,

6. Farouk, M.; Abd Elaziz, O.; Tawakkol, S. M.; Hemdan, A.; Shehata, M. A. Spectrochim. Acta, Part A 2014, 123, 473.

7. Kavathia, A.; Misra, M. Arabian J. Chem. 2017, 10, s3021.

8. Gowri, N.; Vaidhyalingam, V.; Shantha, A. Indian Drugs 2002, 39, 532.

9. Rao, J. R.; Kadam, S. S.; Mahadik, K. R. Indian Drugs 2002, 39, 378.
10. Naidu, K. R.; Kale, U. N.; Shingare, M. S. J. Pharm. Biomed. Anal. $\mathbf{2 0 0 5}, 39,147$

11. Kasawar, G. B.; Farooqui, M. N. Anal. Sci. 2009, 25, 1495.

12. Pilli, N. R.; Inamadugu, J. K.; Mullangi, R.; Karra, V. K.; Vaidya, J. R.; Rao, J. V. Biomed. Chromatogr. 2011, 25, 439.

13. Phani, R. S. C.; Prasad, K. R. S.; Mallu, U. R. Int. J. Pharma Bio Sci. 2013, 4, 440.

14. Ashour, S.; Sakur, A. A.; Kudemati, M. Can. Chem. Trans. 2014, 2, 418.

15. Pan, H. L.; Lin, L. S.; Ding, J. F.; Chen, X. Y.; Zhong, D. F. Yaoxue Xuebao 2014, 49, 95.

16. Gowri, N.; Vaidhyalingam, V.; Shantha, A. Indian Drugs 2003, 40, 645.

17. Meyyanathan, S. N.; Suresh, B. J. Chromatogr. Sci. 2005, 43, 73.

18. El-Gindy, A.; Ashour, A.; Abdel-Fattah, L.; Shabana, M. M. J. Pharm. Biomed. Anal. 2001, 25, 299.

19. Dinc, E. Anal. Lett. 2002, 35, 1021.

20. El-Gindy, A.; Ashour, A.; Abdel-Fattah, L.; Shabana, M. M. J. Pharm. Biomed. Anal. 2001, 25, 171. 
21. Vonaparti, A.; Kazanis, M.; Panderi, I. J. Mass Spectrom. 2006, 41, 593. 22. Manna, L.; Valvo, L.; Alimonti, S. Chromatographia 2001, 53, S271.

23. Hassib, S. T.; El-Sherif, Z. A.; El-Bagary, R. I.; Youssef, N. F. Anal. Lett. 2000, 33, 3225 .

24. Gotti, R.; Andrisano, V.; Cavrini, V.; Bertucci, C.; Furlanetto, S. J. Pharm. Biomed. Anal. 2000, 22, 423.

25. Hillaert, S.; Van den Bossche, W. J. Chromatogr. A 2000, 895, 33.

26. Hillaert, S.; Van Den Bossche, W. J. Pharm. Biomed. Anal. 2001, 25 775 .

27. Hillaert, S.; Vander Heyden, Y.; Van den Bossche, W. J. Chromatogr. A 2002, 978,231

28. Ebeid, W.; Salim, M.; Elkady, E.; Elzahr, A.; El-Bagary, R.; Patonay, G. Pharmazie 2015, 70, 368 .

29. Salim, M. M.; Ebeid, W. M.; El-Enany, N.; Belal, F.; Walash, M.; Patonay, G. J. Sep. Sci. 2014, 37, 1206.

30. https://www.accessdata.fda.gov/drugsatfda docs/label/2009/020033s038lbl.pdf.

31. Barabas, E. S.; Adeyeye, C. M. Crospovidone. Analvtical Profiles of Drug Substances and Excipients, 1996, doi:10.1016/s0099-5428(08)60692-9, 87.

32. https://pubchem.ncbi.nlm.nih.gov/compound/16211421\#section=Solubility.

33. https://pubchem.ncbi.nlm.nih.gov/compound/14833\#section=Solubility.
34. https://pubchem.ncbi.nlm.nih.gov/compound/Titanium-dioxide\#section=Solubility. 35. Moffat, A. C.; Osselton, M. D.; Widdop, B. Clark's Analysis of Drugs and Poisons, The Pharmaceutical Press, London, UK, 2004.

36. Souri, E.; Mottaghi, S.; Zargarpoor, M.; Ahmadkhaniha, R.; Jalalizadeh, H. Acta Chromatogr. 2016, $28,347$.

37. Van Zwieten, P. Clin. Cardiol. 1994, 17, III3.

38. Çelebier, M.; Reçber, T.; Koçak, E.; Altlnöz, S.; Klr, S. J. Chromatogr. Sci. 2016, 54, 216.

39. Prabhune, S. S.; Dighe, V.; Pradhan, N.S. Int. J. Pharm. Pharm. Sci. 2015, 7, 339 .

40. Remko, M. Chem. Pap. 2007, 61, 133.

41. Shihabi, Z. K. Handbook of Analytical Separations, 5 Chapter 3 Capillary electrophoresis for the determination of drugs in biological fluids, 2004, 77.

42. ICH Q2 (R1) Validation of Analytical Procedures: Text and Methodology, Complementary Guideline on Methodology, International Conference on Harmonization, Geneva, November 2005.

43. Armitage, P.; Berry, G. Statistical Methods in Medical Research, 3rd edition, Blackwell, Oxford, UK, 1994, 283.

44. Miller, J. N.; Miller, J. C. Statistics and Chemometrics for Analytical Chemistry, 4th edition, Pearson Education Limited, England, 2000, 126. 